\title{
Process and Productivity Improvement
}

\author{
Syed Muhammad Ali Zaidi \\ (MS/MPHIL Batch \# 03, HIESS, Hamdard University Karachi, Pakistan)
}

\begin{abstract}
The objective of this research project is to analyze the gaps and improve process of a packaging process and managing operations of a pharmaceutical company to carry out with the help of a quality and sigma tools. Analysis gives the effect of material inventory, planning and productivity improvement. The research also aims to find out and eliminate the bottleneck in packaging operations. Our proposed changing in the material inventory and aggregate planning has been drawn in by the industry which optimized their productivity and customer demand by zero production orders delay. Introduction to scrape factor in bill of packaging material and preventive maintenance is found significant increase in productivity of a product and machine efficiency. It results in improvement of the productivity and improves the lead time of a product to prevent any loss which may be customer or financial.
\end{abstract}

Keywords: Blister, Granulation, Production Orders, Scrape Factor, SPC

\section{Introduction}

Every organization tries to achieve their objectives and best quality production by optimum utilization of all resources in the minimum possible time. The time required packing the tablet or capsule depends upon procedures. The pharmaceutical company, situate in Karachi (Sindh, Pakistan) is considered with manufacturing of variety of products and a brand leader brand leader in eleven molecules in the areas of Hepatology, Gastroenterology, Cardiovascular and Diabetes, Pulmonary ENT \& Chest, Rheumatology, and Infectious Diseases. The main aim of this work is to improve the productivity of the industry. Productivity is the key to success and basic objective of every industry. The application of work study in production packaging is to investigate the root causes of production orders delays and it aims at finding the best and most suitable and efficient way of using resources i.e. men, material, machine, money and method.

\section{Literature Review}

The manufacturing of oral solid forms of drug such as tablets is a complex multi-stage process under which the starting materials change their physical characteristics a number of times before the final dosage form is produced. Traditionally, tablets have been made by granulation, a process that imparts two primary requisites to formulate: compatibility and fluidity and then compression. Tablets should be packed before they can be sent for distribution. There are many types of packing use for tablets depend upon the formulation of the medicine e.g. blister packaging, strip packaging, bottle packaging etc.

Blister packs are a common form of packaging. They are safe and easy to use and the user can see the contents without opening the pack. Many pharmaceutical companies use a standard size of blister pack. This saves the cost of different tools and changing the production machinery between products. Sometimes the pack may be perforated so that individual tablets can be detached. This means that the expiry date and the drug's name must be printed on each part of the package. The blister pack itself must remain absolutely flat as it travels through the packaging processes, especially when it is inserted into a carton. Extra ribs are added to the blister pack to improve its stiffness.

Packaging is the technology of enclosing or protecting products for distribution, storage, sale, and use. Packaging also refers to the process of design, evaluation, and production of packages. Packaging can be described as a coordinated system of preparing goods for transport, warehousing, logistics, sale, and end use. Packaging contains, protects, preserves, transports, informs, and sells.

It is sometimes convenient to categorize packages by layer or function: "primary", "secondary", etc.

- Primary packaging is the material that first envelops the product and holds it. This usually is the smallest unit of distribution or use and is the package which is in direct contact with the contents e.g. blisters, glass and plastic bottles, strips, ampoule etc.

- Secondary packaging is outside the primary packaging, perhaps used to group primary packages together e.g. unit carton

- Tertiary packaging is used for bulk handling, warehouse storage and transport shipping. The most common form is a palletized unit load that packs tightly into containers e.g. master carton, shippers etc.

It is important in tablet packing process that all the tablets and packaging material with respect to order were present at the packing machine before start of a process. The main guideline is to ensure that the 
appropriate tablets and packaging material is equal to order size should present at the machine with proper sealed and status. Two basic techniques used for in the pharmaceutical company i.e. online and offline packing. Online packing means primary and secondary packing process performs simultaneously in single process i.e. put tablet from one side and gets the final pack from other side with all regulatory requirements were embossing on the primary and secondary component.

Offline packing means in first phase the tablets packs in a primary component called blister and simultaneously printing process of all regulatory requirements at other station on inkjet printing machine or laser jet printing machine. When these both the process has completed these blisters packs in a printed unit carton at other work station. This also called manual operations.

Productivity means that the efficiency with which output is produced by the utilization of available resources. An effort to save time, energy, power, money and materials to achieve higher production of goods and services at lower cost. Productivity can only be increase if continuously improves the manufacturing process which can be directly dependent on the production planning, breakdown and preventive maintenance, waste reduction and utilization, material handling, inventory control, modernization and up gradation of technology and innovation.

\section{Objectives}

The objectives behind the project are to increase the productivity and to eliminate or reduce the delays of a product during packing process by:

- To find out and eliminate the bottlenecks.

- $\quad$ To reduce the customer delays to minimum level.

\section{Scope of this Research / Work}

The scope of this project only limited to packing operations of a pharmaceutical industry where to analyze and investigate the root causes of increased lead time of a product during the packing process.

\section{Methodology}

In this research project, inductive approach to be adopted to investigate for the actual reasoning behind the problem. The SPC and six sigma basic tools were used in this research. At the start data of all three months were recorded on the sheets, filtering the data problem wise, Pareto analysis and at last analysis of root cause through Ishikawa Root Cause Analysis.

Here, in this research project the area of study was online operations of packaging department one of pharmaceutical industry. The methodology of a project is to collect the data for the three months of all the production orders which were delayed due to any reason during the packing process.

Initially collects all the data of products which were delayed due to any reason during the three months. Details are given I the table 1;

Table 1: List of Orders Delayed During the Month

\begin{tabular}{|c|c|c|}
\hline \multirow{2}{*}{ Month } & \multicolumn{2}{|c|}{ Production Orders Delayed } \\
\cline { 2 - 3 } & Online & Offline \\
\hline September & 10 & 12 \\
\hline October & 15 & 18 \\
\hline November & 12 & 20 \\
\hline
\end{tabular}

In second stage separate online and offline packed products and calculate the total down time of both the process which suffered the organization due to the production orders delay. As data during the three months which clearly shows that the heavy financial impact of orders delays due to online operations as shown in Table 2.

Table 2: List of Total Orders Delayed and Downtime

\begin{tabular}{|c|c|c|}
\hline Operations & Total Orders Delays & $\begin{array}{c}\text { Downtime } \\
\text { (Time Loss in hours) }\end{array}$ \\
\hline Online & 37 & 43.7 \\
\hline Offline / Manual & 50 & 8.33 \\
\hline Total & $\mathbf{8 7}$ & $\mathbf{5 2 . 0 3}$ \\
\hline
\end{tabular}

In third phase we analyze from the data, the reasons and root cause behind these delays, shown in Table 3. 
Table 3: List of Reasons for Delay

\begin{tabular}{|c|c|c|}
\hline S No. & Reasons & Frequency \\
\hline 1 & Inset Card (leaflet) & 27 \\
\hline 2 & Unit Carton & 30 \\
\hline 3 & Rework & 10 \\
\hline 4 & Machine Malfunction & 7 \\
\hline \multicolumn{2}{|c|}{ Total } & $\mathbf{7 4}$ \\
\hline
\end{tabular}

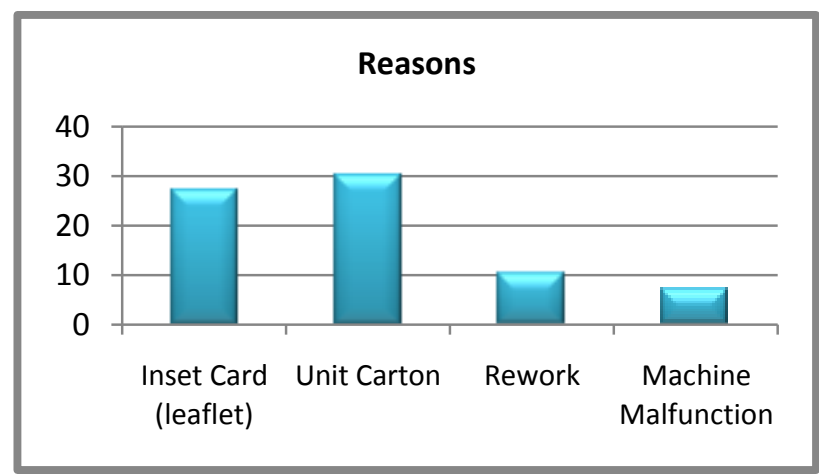

Fig 1: Graph of Reasons for Delay

Further filtering the investigation and find out what is major root causes behind these problems. Table 4 shows the details.

Table 4: List of Root Causes

\begin{tabular}{|c|l|c|}
\hline S No. & \multicolumn{1}{|c|}{ Root Causes } & Frequency \\
\hline 1 & Packaging Material shortage from vender end & 18 \\
\hline 2 & Rejection during process due to human error & 2 \\
\hline 3 & Rejection during process due to machine & 23 \\
\hline 4 & Rejection due to defected packaging material & 53 \\
\hline \multicolumn{2}{|c|}{ Total } & $\mathbf{9 6}$ \\
\hline
\end{tabular}

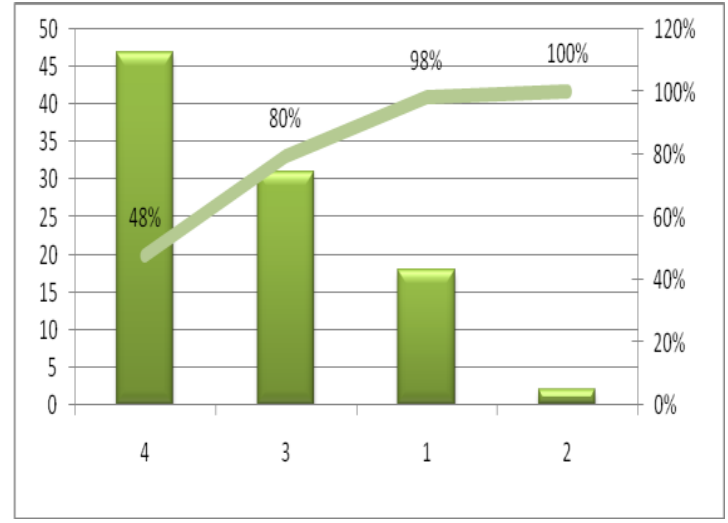

Fig 2: Pareto Analysis of Reasons for Delay

\section{Results and Discussions}

According to the results analyzed, investigated and interpreted through fish bone analysis it revealed that the frequency of production delays of off-online process is greater than the on-line process but the table 2 shows that the downtime of these delays is higher for the on line process. This higher valve just because of automated operations because the change over from one product to second product is high in online process as compared to offline process.

When we analyzing the others factors and the practices which effects these factors, find the following results; 


\subsection{Men}

Operator skills, motivation, knowledge and training level had analyzed which was found satisfactory and well aware of all the requirements.

\subsection{Machine}

All parts of machine were checked with help of engineering team and operator reveals that the certain parts of machine were not working properly and when the planned and preventive maintenance e schedule checked it found that the schedule not follow.

\subsection{Material}

Material storage condition as per standard and satisfactory. As per operator comments that short quantity was observed and also reported in the sealed box of packaging material. As per packaging material analyst comments that sampling and analysis of packaging material were perform as per standard procedures and military rule was follow for sampling.

\subsection{Method}

Materials handled and transported properly and as per standard procedures were followed. cGMP practices were followed.

\subsection{Measurement}

Packaging material analyze as per standard procedure defined internally meet the WHO guideline.

\section{Recommendation}

Following are the recommendations of the problem to improve up to minimum level.

a) Every organization may have made substantial efforts to record inventory accurately; these records must be verified through a continuing audit. Such audits are known as cycle counting. With cycle counting procedures, items are counted, records are verified and inaccuracies are periodically documented and timely communicated to vender as also recommended by Author Jay Heizer and Barry Render, Sugar Confectionery Manufacture (1999) by E. B. Jackson, chapter 11 in their book Operational Management.

b) Secondly shared all data of shortage and defects of packaging material with vender and told them to investigate the root cause at their end and submit the investigation report.

c) As results from above analyses that the second major factor for delays in orders is the machine malfunction, so it is strongly recommended that preventive maintenance should be as per schedule. It is also recommended to calculate and analyze the overall equipment efficiency (OEE) on daily basis and take necessary accordingly.

d) It is also recommended that add scrap factor in the bill of material (BOM) if it is financially feasible as in existing BOM of all products there is no scarp factor.

\section{Conclusion}

From all above analyzes it is conclude that most of the orders delayed due to the machine malfunction and, defected packaging material and short supply from vender end. So, it is concluded that immediately works on recommendations to avoid further delays in orders.

\section{References}

[1] Rajkumar P. Patil, Shakthi Prakash M R, Productivity Enhancement and Measurement in Pharmaceutical Industry, International Journal of Pharma. Research \& Development, IJPRD/2011/PUB/ARTI/VOV-3/ISSUE-1/MARCH/018

[2] John Dramm, Results-Driven Approach to Improving Quality and Productivity.

[3] Donna Knight, How to Improve Pharmaceutical Productivity. Available from: http://www.ehow.com/how_6982231_imporvepharmaceutical productivity.html\#ixzz19OqcJgqQ.

[4] Aftab Ahmed, Imtiyaz Khan \& M.K. Ghosh, SPC Implementation in Pharmaceutical Industry for Material Flow Management, Interscience Management Review (IMR), ISSN: 2231-1513, Volume- 2, Issue-3, 2012.

[5] Jay Heizer and Barry Render, Sugar Confectionery Manufacture (1999) by E. B., "Operational Management", Tenth Edition, Jackson, chapter 11.

[6] wikipedia.org/wiki/Tableting.

[7] Soroka (2002) Fundamentals of Packaging Technology, Institute of Packaging Professionals ISBN 1-930268-25-4. 